\title{
Incidence, risk factors and clinical outcomes of acute kidney injury after heart transplantation: a retrospective single center study
}

Yi-Yao Jiang ${ }^{1,2}$, Xiang-Rong Kong ${ }^{1 *}$, Fen-Long Xue ${ }^{1}$, Hong-Lei Chen ${ }^{1}$, Wei Zhou ${ }^{1}$, Jun-Wu Chai ${ }^{1}$, Fei Wu ${ }^{1}$, Shan-Shan Jiang ${ }^{1}$, Zhi-Long $\mathrm{Li}^{1}$ and Kai Wang ${ }^{1}$

\begin{abstract}
Objectives: This study aimed to identify the incidence rate of Acute kidney injury (AKI) in our center and predict inhospital mortality and long-term survival after heart transplantation (HTx).

Methods: This single-center, retrospective study from October 2009 and March 2020 analyzed the pre-, intra-, and postoperative characteristics of 95 patients who underwent HTx. AKI was defined according to the Kidney Disease: Improving Global Outcomes (KDIGO) criteria. Risk factors were analyzed by multivariable logistic regression models. The log-rank test was used to compare long-term survival.

Results: Thirty-three (34.7\%) patients developed AKI. The mortality in hospital in HTx patients with and without AKI were 21.21 and $6.45 \%$, respectively $(P<0.05)$. Recipients in AKI who required renal replacement therapy (RRT) had a hospital mortality rate of $43.75 \%$ compared to $6.45 \%$ in those without AKI or RRT ( $P<0.0001$ ). A long cardiopulmonary bypass (CPB) time (OR:11.393, 95\% Cl: 2.183 to $59.465, P=0.0039)$ was positively related to the occurrence of AKI. A high intraoperative urine volume (OR: $0.031,95 \% \mathrm{Cl}: 0.005$ to $0.212, P=0.0004$ ) was negatively correlated with AKI. AKI requiring RRT $(\mathrm{OR}, 11.348 ; 95 \% \mathrm{Cl}, 2.418-53.267, P=0.002)$ was a risk factor for mortality in hospital. Overall survival in patients without AKI at 1 and 3 years was not different from that in patients with AKI $(P=0.096)$.
\end{abstract}

Conclusions: AKI is common after HTX. AKI requiring RRT could contribute powerful prognostic information to predict mortality in hospital. A long CPB time and low intraoperative urine volume are associated with the occurrence of AKI.

Keywords: Acute kidney injury, Heart transplantation, Mortality, Outcomes

\footnotetext{
* Correspondence: Kongxiangrong001@sina.com

'Department of Cardiovascular Surgery, Tianjin First Center Hospital and NanKai University, Tianjin, China

Full list of author information is available at the end of the article
}

(c) The Author(s). 2020 Open Access This article is licensed under a Creative Commons Attribution 4.0 International License, which permits use, sharing, adaptation, distribution and reproduction in any medium or format, as long as you give appropriate credit to the original author(s) and the source, provide a link to the Creative Commons licence, and indicate if changes were made. The images or other third party material in this article are included in the article's Creative Commons licence, unless indicated otherwise in a credit line to the material. If material is not included in the article's Creative Commons licence and your intended use is not permitted by statutory regulation or exceeds the permitted use, you will need to obtain permission directly from the copyright holder. To view a copy of this licence, visit http://creativecommons.org/licenses/by/4.0/ The Creative Commons Public Domain Dedication waiver (http://creativecommons.org/publicdomain/zero/1.0/) applies to the data made available in this article, unless otherwise stated in a credit line to the data. 


\section{Introduction}

Heart transplantation (HTx) is a generally successful procedure for patients with end-stage heart failure, improving their survival and quality of life [1]. Acute kidney injury (AKI) is a frequent complication following HTx. With an incidence ranging from 14 to $76 \%$, it is a significant contributor to high morbidity and mortality [2-7]. There are various causes of AKI, such as renal hypoperfusion, prolonged cardiopulmonary bypass (CPB), and nephrotoxicity of immunosuppressive drugs [8]. Therefore, there is a need to identify high-risk factors, reduce the life-threatening outcomes of AKI, and enhance the long-term survival rates in HTx patients.

Scoring systems for the quantification of AKI have been applied in clinical studies. These criteria included the Risk/Injury/Failure/Loss/End-stage (RIFLE) criteria, the Acute Kidney Injury Network (AKIN) criteria, and the Kidney Disease: Improving Global Outcomes (KDIGO) criteria [9-11]. Based on these criteria, AKI can be defined and staged. It is important to note that despite different performances of different scoring systems, a mild to modest form of AKI does not play a significant role in predicting poor long-term outcomes [12]. However, patients who develop severe AKI frequently receive renal replacement therapy (RRT) as a salvage treatment. The need for RRT has been reported to be one of the most important predictors of a poor prognosis after HTx [13]. Although some clinical outcomes associated with AKI requiring RRT have been described, its impact on long-term survival has not been addressed.

The aims of this study were to (1) evaluate the incidence of AKI after HTx in our center by using the KDIGO criteria, (2) identify risk factors for AKI and inhospital mortality after HTx, and (3) explore long-term survival in AKI patients.

\section{Methods}

\section{Patient population}

Between October 2009 and March 2020, 113 patients were transplanted. According to exclusion criteria, 10 patients were underwent for combined heart-kidney transplant were not included; 8 patients who were lost to follow-up were also excluded. We included 95 patients in the final analysis. All patients were followed in the outpatient department.

\section{Perioperative management}

A biatrial technique was performed in the HTx procedure. All patients received methylprednisolone intraoperatively $(500 \mathrm{mg}$ when the aortic cross clamp was released) followed by $120 \mathrm{mg}$ q8h intravenous for the first $24 \mathrm{~h}, 120 \mathrm{mg}$ q12h for the second $24 \mathrm{~h}, 120 \mathrm{mg}$ once daily for the third $24 \mathrm{~h}$ and basiliximab (20 mg loading dose in the operating room and $20 \mathrm{mg}$ the fourth day). On the fourth day postoperation, tacrolimus and mycophenolate mofetil was started at an oral dose of $1.5 \mathrm{mg}$ and $500 \mathrm{mg}$ twice daily, respectively. Tacrolimus and mycophenolate mofetil were prescribed for the rest of their lives. Further, dosing was based on tacrolimus whole-blood trough concentrations at 6 a.m. (12 h postdose). A whole-blood tacrolimus trough concentration between 7 and $15 \mathrm{ng} / \mathrm{ml}$ was considered in the first 3 months and thereafter tapered towards $5-10 \mathrm{ng} / \mathrm{ml}$. Accompanying immunosuppression comprised corticosteroids, prednisolone was started $28 \mathrm{mg}$ orally on the fourth day postoperation, followed by $24 \mathrm{mg}$ once daily and tapered off to $8 \mathrm{mg}$ once daily orally.

\section{Outcome measure}

AKI was classified according to the KDIGO criteria [11]. The KDIGO criteria recognize 3 stages of AKI severity based on serum creatinine ( $\mathrm{SCr}$ ) levels and urine output. The definition of AKI was based on peak creatinine within 7 days postoperation. The administration of loop diuretics is a commonly used method in the postoperative period and in the early management of AKI, at least in patients with volume overload and/or oliguria. Indications for RRT were stage 3 AKI combined with one of the following: hyperkalemia, severe hypervolemia, uncorrectable metabolic acidosis or serious uremia.

Continuous variables are presented as mean \pm standard deviation, while categorical or integer variables are presented as number and percentage. To compare values between two groups, Student's $t$ test was used for normally distributed numerical variables, and Wilcoxon rank test for nonnormally ones. One-way analysis of covariance (ANOVA) or Kruskal-Wallis test was used for comparisons more than two groups. When there was a statistical significance among groups, SNK method was used to perform comparison between groups. Categorical or integer parameters compared by Fisher's exact test or Chi-square test. Other continuous variables were expressed as median and interquartile (25th to 75th percentile) range and compared by Mann-Whitney U-test or Kruskal-Wallis test. Survival analysis was performed using log-rank test. Cox proportional hazards model were used to identify variables independently associated with mortality. All statistical procedures were performed using SAS 9.4 (SAS Institute Inc. Cary, NC, USA) and GraphPad Prism 5.0 (GraphPad Software Inc., La Jolla, USA). A two-tailed $P$ value $<0.05$ was considered statistically significant.

\section{Results}

Table 1 shows the demographics and perioperative characteristics of the HTx recipients stratified into 3 groups by the estimated glomerular filtration rate (eGFR). 
Table 1 Demographics and Perioperative Characteristics of the HTx Recipients Stratified by eGFR

\begin{tabular}{|c|c|c|c|c|c|}
\hline & \multirow{2}{*}{$\begin{array}{l}\text { Overall } \\
(n=95)\end{array}$} & \multicolumn{3}{|c|}{ eGFR $\left(\mathrm{ml} / \mathrm{min} / 1.73 \mathrm{~m}^{2}\right)$} & \multirow[t]{2}{*}{$P$ value } \\
\hline & & $<30(n=25)$ & $30-59(n=61)$ & $\geq 60(n=9)$ & \\
\hline \multicolumn{6}{|l|}{ Demographic data } \\
\hline Age, years & $54.31 \pm 11.92$ & $58.88 \pm 9.75$ & $55.15 \pm 9.20$ & $35.89 \pm 17.20$ & $0.0007^{*}$ \\
\hline Sex, men, n (\%) & $81(85.26)$ & 19(76.00) & $54(88.52)$ & $8(88.89)$ & 0.318 \\
\hline $\mathrm{BMI}\left(\mathrm{kg} / \mathrm{m}^{2}\right)$ & $24.54 \pm 3.83$ & $23.89 \pm 3.15$ & $24.70 \pm 4.08$ & $25.25 \pm 3.92$ & 0.575 \\
\hline History of alcohol & $29(30.53)$ & $10(40.00)$ & $17(27.87)$ & $2(22.22)$ & 0.464 \\
\hline History of smoking & 63(66.32) & $16(64.00)$ & $41(67.21)$ & $6(66.67)$ & 0.960 \\
\hline Hypertension & $39(41.05)$ & $15(60.00)$ & $21(34.43)$ & 3(33.33) & 0.083 \\
\hline Diabetes mellitus & 34(35.79) & $12(48.00)$ & 19(31.15) & 3(33.33) & 0.334 \\
\hline Chronic kidney disease & $20(21.05)$ & $12(48.00)$ & $6(9.84)$ & $2(22.22)$ & $0.0005^{*}$ \\
\hline \multicolumn{6}{|l|}{ Pretransplant characteristics } \\
\hline DCM & $38(40.00)$ & $7(28.00)$ & $26(42.62)$ & $5(55.56)$ & 0.279 \\
\hline CAD & $27(28.42)$ & $9(36.00)$ & $16(26.23)$ & $2(22.22)$ & 0.604 \\
\hline Valve disease & $15(15.79)$ & $3(12.00)$ & 10(16.39) & $2(22.22)$ & 0.756 \\
\hline Pre-PCl & $11(11.58)$ & $4(16)$ & $7(11.48)$ & $0(0)$ & 0.441 \\
\hline ICD implantation & $3(3.16)$ & $2(8.00)$ & $1(1.64)$ & $0(0)$ & 0.267 \\
\hline LVAD implantation & $1(1.05)$ & $0(0)$ & $0(0)$ & 1(11.11) & $0.008^{*}$ \\
\hline Cardiac tumor & $1(1.05)$ & $0(0)$ & $1(1.64)$ & $0(0)$ & 0.755 \\
\hline EF pre-HTx (\%) & $28(23,31)$ & $30(24,33)$ & $26(23,30)$ & $25(20,30)$ & 0.257 \\
\hline Creatinine (mg/dL) & $1.14(0.95,1.27)$ & $1.60(1.33,1.91)$ & $1.10(0.95,1.22)$ & $0.76(0.70,0.87)$ & $<.0001^{*}$ \\
\hline \multicolumn{6}{|l|}{ Intraoperative characteristics } \\
\hline CPB duration (min) & $225(183,262)$ & $225(180,270)$ & $220(193,255)$ & $210(180,225)$ & 0.822 \\
\hline Blood transfusion (ml) & $1440(1100,2100)$ & $1400(1100,2000)$ & $1440(1100,2200)$ & $1640(1000,2050)$ & 0.849 \\
\hline Infusion (ml) & $1810(1320,2440)$ & $2000(1505,2580)$ & $1800(1320,2350)$ & $1700(1190,1925)$ & 0.483 \\
\hline Blood loss (ml) & $1000(1000,2200)$ & $1500(1000,2500)$ & $1000(1000,2000)$ & $1500(1000,2000)$ & 0.804 \\
\hline Urine volume (ml) & $1800(1200,2500)$ & $1300(770,1650)$ & $2000(1300,2500)$ & $2150(2000,2900)$ & $0.001^{*}$ \\
\hline IABP/ECMO & $6(6.32)$ & $4(16.00)$ & $2(3.28)$ & $0(0)$ & 0.065 \\
\hline \multicolumn{6}{|l|}{ Postoperative characteristics } \\
\hline \multicolumn{6}{|l|}{ AKI stage } \\
\hline NO-AKI & $62(65.26)$ & $16(64.00)$ & $40(65.57)$ & $6(66.67)$ & 0.428 \\
\hline Stage 1 & $9(9.47)$ & $0(0)$ & $8(13.11)$ & $1(11.11)$ & \\
\hline Stage 2 & $8(8.42)$ & $2(8.00)$ & $4(6.56)$ & $2(22.22)$ & \\
\hline Stage 3 & $16(16.84)$ & $7(28.00)$ & $9(14.75)$ & $0(0)$ & \\
\hline \multicolumn{6}{|l|}{ Urine volume } \\
\hline 1st Day after operation & $2200(1980,2805)$ & $2100(1965,2485)$ & $2200(1980,2735)$ & $2525(2115,3320)$ & 0.194 \\
\hline 2nd Day after operation & $2125(1765,2505)$ & $1935(1400,2498)$ & $2135(1845,2500)$ & $2425(2005,2970)$ & 0.081 \\
\hline 3rd Day after operation & $2110(1860,2050)$ & $2050(1400,2498)$ & $2145(1930,2450)$ & $2305(2050,2440)$ & 0.300 \\
\hline Mechanical ventilation (min) & $1080(840,2220)$ & 1920(960,3720) & $1040(783,2100)$ & $960(720,1410)$ & 0.134 \\
\hline RRT & 16(16.84) & $7(28.00)$ & $9(14.75)$ & $0(0)$ & 0.123 \\
\hline Time from operation to discharge (days) & $26(22,33)$ & $29(23,37)$ & $26(22,32)$ & $24(20,26)$ & 0.370 \\
\hline Death & 15(15.79) & $4(16.00)$ & 10(16.39) & $1(11.11)$ & 0.921 \\
\hline Mortality in hospital & $11(11.58)$ & $4(16.00)$ & $6(9.84)$ & $1(11.11)$ & 0.719 \\
\hline Death within 1 year & $3(3.16)$ & $0(0)$ & $3(4.92)$ & $0(0)$ & 0.422 \\
\hline Follow-up days & $608(303,1180)$ & $555(341,951)$ & $692(276,1180)$ & $1451(497,2132)$ & 0.199 \\
\hline
\end{tabular}

* $P<0.05$; eGFR was calculated using the Chronic Kidney Disease Epidemiology collaboration equation. HTx Heart transplantation, eGFR Estimated glomerular filtration rate, $B M I$ Body mass index, DCM Dilated cardiomyopathy, $C A D$ Coronary arterial disease, Pre-PCI Previous percutaneous coronary intervention, $I C D$ Implantable cardioverter defibrillator, LVAD Left ventricular assist device, CPB Cardiopulmonary bypass, RRT Renal replacement therapy. Numbers in brackets are interquartile ranges (IQRs). ANOVA was applied to the BMI variable because of its normal distribution. The Kruskal-Wallis test was used to compare other variables 
Patients in the GFR $<30 \mathrm{ml} / \mathrm{min} / 1.73 \mathrm{~m}^{2}$ group were older than those in the eGFR $\geq 60 \mathrm{ml} / \mathrm{min} / 1.73 \mathrm{~m}^{2}$ group $(P<0.001)$, and frequency of chronic kidney disease and the creatinine levels were higher in the GFR $<30 \mathrm{ml} /$ $\mathrm{min} / 1.73 \mathrm{~m}^{2}$ group than in the other groups $(P=0.0005$ and $P<0.0001$, respectively). However, there was no difference in body mass index (BMI) or left ventricular ejection fraction (LVEF) among the groups $(P=0.575$ and 0.257 , respectively). In addition, the three groups had a similar frequency of dilated cardiomyopathy $(\mathrm{DCM})$, coronary artery disease (CAD), valve disease, and pre-percutaneous coronary intervention $(\mathrm{PCI})(P=$ $0.279,0.604,0.756$ and 0.441 , respectively). Intraoperatively, patients in the $G F R<30 \mathrm{ml} / \mathrm{min} / 1.73 \mathrm{~m}^{2}$ group had a longer duration of $\mathrm{CPB}$ and more infusion than the patients in the other groups, but there was no statistical significance $(P>0.05)$. Although there was decreased urine volume during the operation in the GFR < $30 \mathrm{ml} / \mathrm{min} / 1.73 \mathrm{~m}^{2}$ group $(P=0.001)$, there was no difference in time from operation to discharge, mortality in hospital, death within 1 year, or the incidence of AKI between the groups $(P>0.05)$.

Of the 95 HTx recipients who were enrolled, 33 patients fulfilled the criteria for AKI, and 62 patients were assigned to the non-AKI group (Table 2). Although there was no difference in most perioperative variables, the CPB time, blood loss and frequency of application of intra-aortic balloon pump with venoarterial extracorporeal membrane oxygenation (IABP/ECMO) during the operation were higher in the AKI group than in the non-AKI group $(P=0.0149,0.0312$ and 0.0102 , respectively). Moreover, the urine volume during and after the operation was lower in the AKI group $(P<0.005)$. The frequency of RRT was higher in the AKI group than in the non-AKI group $(P<0.0001)$.

Table 3 shows the demographics and perioperative characteristics of $95 \mathrm{HTx}$ recipients stratified into 3 groups by post-HTx RRT. Intraoperatively, the AKI with RRT group had a longer CPB time, more blood loss, lower urine volume and a higher frequency of IABP/ ECMO than the other groups $(P=0.0088,0.0298,0.0021$ and $<0.0001$, respectively). Postoperatively, there were significant differences in urine volume, mechanical ventilation rate and mortality in hospital.

The overall hospital mortality was $11.58 \%(11 / 95)$. The orrcurence of AKI was associated with mortality in hospital $(P=0.0383)$. Patients requiring RRT had a hospital mortality of $43.75 \%(7 / 16)$ compared with $6.45 \%(4 / 62)$ in those patients without AKI or RRT (Fig. 3 and Table $3)$. The causes of death were as follows: sepsis $(n=3)$, respiratory failure $(n=2)$, cerebral hemorrhage $(n=1)$, pulmonary embolism $(\mathrm{n}=1)$, gastrointestinal bleeding $(\mathrm{n}=1)$, disseminated intravascular coagulation $(\mathrm{n}=1)$, shock $(\mathrm{n}=1)$, and 1 patients without diagnosis.
Multivariate logistic regression analysis suggested that AKI requiring RRT was a risk factor independently associated with hospital mortality (Table 4).

The median duration of follow-up after hospital discharge was 608 days (interquartile range, 303-1180 days) with a maximum of 3405 days. The clinical outcomes are summarized by eGFR stratification in Fig. 1. There were no differences in long-term survival among the 3 groups stratified by eGFR $(P=0.897)$. When stratified by AKI, there was no difference in the overall 3-year survival rates $(P=0.096)$ (Fig. 2$)$. However, the survival rate was $72.16 \pm 16.38 \%$ in the AKI with RRT group, while the survival rate was $89.43 \pm 2.33 \%$ in the non-AKI without RRT group $(P<0.001)$ (Fig. 3$)$. A total of 4 deaths were observed during the follow-up period. The causes of death within 1 year were as follows: sepsis $(n=2)$ and tumor metastasis $(n=1)$. One patient requiring RRT passed away due to cerebral infarction at 3 years after HTx.

The multivariable model for AKI is summarized in Table 5. When the CPB time is more than $265 \mathrm{~min}$, it was positively related to the occurrence of AKI (OR: 11.393, 95\% CI: 2.183 to $59.465, P=0.0039$ ). A decreased intraoperative urine volume, less than $1700 \mathrm{ml}$, it may positively correlated with AKI (OR: 0.181, 95\% CI: 0.042 to $0.774, P=0.0211$ ).

\section{Discussion}

In our retrospective analysis, we found that AKI was a frequent complication of HTx, with an incidence of $34.7 \%$. We also showed that a relatively short CPB time ( $\leq 265 \mathrm{~min}$ ) and increased intraoperative urine volume could prevent the occurrence of AKI. Furthermore, AKI requiring RRT was an independent risk factor for inhospital mortality after HTx. Finally, AKI requiring RRT was not associated with long-term mortality.

Severe AKI is an important independent contributor to mortality in the HTx population. Accumulating evidence indicates that AKI requiring RRT could be a strong predictor of adverse clinical outcomes. In Renata's study, patients with AKI, especially those requiring RRT (46.9\%), had higher hospital mortality (16\%) than those without AKI [14]. However, after hospital discharge, AKI was not associated with poor long-term outcomes. With a median follow-up after hospital discharge of 6.7 years, overall survival at 1,5 , and 10 years was 95.4, 85.1, and $75.4 \%$ and 85.2, 69.8 and $63.5 \%$ among patients with AKI stages 2 and 3, respectively [14]. Fortrie's findings showed that one-year mortality rates in patients without AKI and with AKI stages 1, 2, and 3 were $4.8,7.6,11.8$, and $14.7 \%$, respectively [7]. In an extensive follow-up of $471 \mathrm{HTx}$ patients over a period up to 26 years, no association was found between the development of AKI and long-term mortality or chronic RRT 
Table 2 Demographics and Perioperative Characteristics of HTx Recipients Stratified by AKI

\begin{tabular}{|c|c|c|c|}
\hline & AKI $(n=33)$ & Non-AKI $(n=62)$ & $P$ value \\
\hline \multicolumn{4}{|l|}{ Demographic data } \\
\hline Age, years & $55.12 \pm 12.02$ & $53.87 \pm 11.94$ & 0.534 \\
\hline$<60$ & 19(57.58) & $36(58.06)$ & 0.964 \\
\hline$\geq 60$ & $14(42.42)$ & $26(41.94)$ & \\
\hline Sex, men, n (\%) & $31(93.94)$ & $50(80.65)$ & 0.083 \\
\hline $\mathrm{BMI}\left(\mathrm{kg} / \mathrm{m}^{2}\right)$ & $25.29 \pm 4.32$ & $24.14 \pm 3.51$ & 0.164 \\
\hline History of alcohol & $8(24.24)$ & $21(33.87)$ & 0.335 \\
\hline History of smoking & $23(69.70)$ & $40(64.52)$ & 0.613 \\
\hline Hypertension & $17(51.52)$ & $22(35.48)$ & 0.133 \\
\hline Diabetes mellitus & $14(42.42)$ & $20(32.26)$ & 0.328 \\
\hline Chronic kidney disease & $10(30.3)$ & 10(16.13) & 0.109 \\
\hline \multicolumn{4}{|l|}{ Pretransplant characteristics } \\
\hline DCM & $8(24.24)$ & $30(48.39)$ & 0.023 \\
\hline$C A D$ & 13(39.39) & $14(22.58)$ & 0.085 \\
\hline Valve disease & $5(15.15)$ & 10(16.13) & 0.902 \\
\hline Pre-PCl & $7(21.21)$ & $4(6.45)$ & $0.033^{*}$ \\
\hline ICD implantation & $0(0)$ & $3(4.84)$ & 0.202 \\
\hline LVAD implantation & $1(3.03)$ & $0(0)$ & 0.347 \\
\hline Cardiac tumor & $0(0)$ & $1(1.61)$ & 0.653 \\
\hline EF pre-HTx (\%) & $28(25,31)$ & $27(22,30)$ & 0.359 \\
\hline Creatinine (mg/dL) & $1.14(1,1.27)$ & $1.14(0.95,1.27)$ & 0.617 \\
\hline GFR $\left(\mathrm{ml} / \mathrm{min} / 1.73 \mathrm{~m}^{2}\right)$ & $38.58(29.74,45.60)$ & $38.05(29.68,46.23)$ & 0.988 \\
\hline$<30$ & $9(27.27)$ & $16(25.81)$ & 0.0986 \\
\hline $30-59$ & $21(63.64)$ & $40(64.52)$ & \\
\hline$\geq 60$ & $3(9.09)$ & $6(9.68)$ & \\
\hline \multicolumn{4}{|l|}{ Intraoperative characteristics } \\
\hline CPB duration (min) & $240(210,270)$ & $209(180,240)$ & $0.0149^{*}$ \\
\hline Blood transfusion (ml) & $1470(1300,2000)$ & $1440(1000,2100)$ & 0.630 \\
\hline Infusion (ml) & $2050(1350,2980)$ & $1800(1300,2220)$ & 0.108 \\
\hline Blood loss (ml) & $1600(1000,3000)$ & $1000(1000,2000)$ & $0.0312^{*}$ \\
\hline Urine volume $(\mathrm{ml})$ & $1500(850,2000)$ & $2000(1300,2700)$ & $0.0006^{*}$ \\
\hline IABP/ECMO & $5(15.15)$ & $1(1.61)$ & $0.0102^{*}$ \\
\hline \multicolumn{4}{|l|}{ Postoperative characteristics } \\
\hline \multicolumn{4}{|l|}{ Urine volume } \\
\hline 1st Day after operation & $2100(1720,2965)$ & $2200(2030,2795)$ & 0.223 \\
\hline 2nd Day after operation & $1850(1260,2335)$ & $2197.5(1875,2510)$ & $0.017^{*}$ \\
\hline 3rd Day after operation & $2015(1260,2155)$ & $2180(2005,2615)$ & $0.0003^{*}$ \\
\hline RRT & $16(48.48)$ & $0(0)$ & $<.0001^{*}$ \\
\hline Mechanical ventilation (min) & 1380(840-3780) & $1020(780,2080)$ & 0.109 \\
\hline Time from operation to discharge (days) & $29(24,51)$ & $25(22,30)$ & $0.022^{*}$ \\
\hline Death & $8(24.24)$ & $7(11.29)$ & 0.101 \\
\hline Mortality in hospital & $7(21.21)$ & $4(6.45)$ & $0.038^{*}$ \\
\hline Death within 1 year & $0(0)$ & $3(4.84)$ & 0.549 \\
\hline Follow-up days & $510(258,1423)$ & $658.5(382,1162)$ & 0.514 \\
\hline
\end{tabular}

* $P<0.05$; ANOVA was applied to the BMI variable because of its normal distribution. The Kruskal-Wallis test was used to compare other variables 
Table 3 Demographics and Perioperative Characteristics of HTx Recipients Stratified by RRT

\begin{tabular}{|c|c|c|c|c|}
\hline & $\begin{array}{l}\text { Non-AKI without RRT } \\
(n=62)\end{array}$ & AKI without RRT $(n=17)$ & $\begin{array}{l}\text { AKI with RRT } \\
(n=16)\end{array}$ & $P$ value \\
\hline \multicolumn{5}{|l|}{ Demographic data } \\
\hline Age, years & $53.87 \pm 11.94$ & $52.24 \pm 14.63$ & $58.19 \pm 7.77$ & 0.597 \\
\hline$<60$ & $36(58.06)$ & 10(58.82) & $9(56.25)$ & 0.988 \\
\hline$\geq 60$ & $26(41.94)$ & $7(41.18)$ & $7(43.75)$ & \\
\hline Sex, men, n (\%) & $5(80.65)$ & $17(100)$ & $14(87.50)$ & 0.135 \\
\hline $\mathrm{BMI}\left(\mathrm{kg} / \mathrm{m}^{2}\right)$ & $24.14 \pm 3.51$ & $25.11 \pm 4.52$ & $25.47 \pm 4.23$ & 0.368 \\
\hline History of alcohol & $21(33.87)$ & $2(11.76)$ & $6(37.50)$ & 0.176 \\
\hline History of smoking & $40(64.52)$ & 13(76.47) & $10(62.50)$ & 0.616 \\
\hline Hypertension & $22(35.48)$ & $9(52.94)$ & $8(50.00)$ & 0.318 \\
\hline Diabetes mellitus & $20(32.26)$ & 6(35.29) & $8(50.00)$ & 0.422 \\
\hline Chronic kidney disease & 10(16.13) & $3(16.13)$ & $7(43.75)$ & 0.052 \\
\hline \multicolumn{5}{|l|}{ Pretransplant characteristics } \\
\hline DCM & $30(48.39)$ & $5(29.41)$ & $3(18.75)$ & 0.062 \\
\hline$C A D$ & $14(22.58)$ & $5(29.41)$ & $8(50.00)$ & 0.097 \\
\hline Valve disease & 10(16.13) & $2(11.76)$ & $3(18.75)$ & 0.854 \\
\hline Pre-PCl & $4(6.45)$ & $5(29.41)$ & $2(12.50)$ & $0.033^{*}$ \\
\hline ICD implantation & $3(4.84)$ & $0(0)$ & $0(0)$ & 0.442 \\
\hline LVAD implantation & $0(0)$ & $1(5.88)$ & $0(0)$ & 0.098 \\
\hline Cardiac tumor & $1(1.61)$ & $0(0)$ & $0(0)$ & 0.764 \\
\hline EF pre-HTx (\%) & $27(22,30)$ & $28(25,30)$ & $28.5(24.5,33.5)$ & 0.571 \\
\hline Creatinine (mg/dL) & $1.14(0.95,1.27)$ & $1.14(1.00,1.19)$ & $1.25(1.04,1.51)$ & 0.244 \\
\hline GFR $\left(\mathrm{ml} / \mathrm{min} / 1.73 \mathrm{~m}^{2}\right)$ & $38.05(29.68,46.23)$ & $39.18(35.39,47.80)$ & $37.36(24 \cdot 10,40.43)$ & 0.183 \\
\hline$<30$ & $16(25.81)$ & $2(11.76)$ & $7(43.75)$ & 0.189 \\
\hline $30-59$ & $40(64.52)$ & 12(70.59) & $9(56.25)$ & \\
\hline$\geq 60$ & $6(9.68)$ & $3(17.65)$ & $0(0)$ & \\
\hline \multicolumn{5}{|l|}{ Intraoperative characteristics } \\
\hline CPB duration (min) & $209(180,240)$ & $210(210,240)$ & $269(232.5297 .5)$ & $0.0088^{*}$ \\
\hline Blood transfusion (ml) & $1440(1000,2100)$ & $1440(1000,1812)$ & $1500(1300,2625)$ & 0.499 \\
\hline Infusion (ml) & $1800(1300,2220)$ & $1980(1400,2950)$ & $2055(1285,3025)$ & 0.275 \\
\hline Blood loss (ml) & $1000(1000,2000)$ & $1000(1000,2500)$ & $2200(1300,3350)$ & $0.0298^{*}$ \\
\hline Urine volume (ml) & $2000(1300,2700)$ & $1500(1000,2000)$ & $1100(710,2000)$ & $0.0021^{*}$ \\
\hline IABP/ECMO & $1(1.61)$ & $0(0)$ & $5(31.25)$ & $<.0001^{*}$ \\
\hline \multicolumn{5}{|l|}{ Postoperative characteristics } \\
\hline \multicolumn{5}{|l|}{ Urine volume } \\
\hline 1st Day after operation & $2200(2030,2795)$ & $2470(2100,3010)$ & $1597.5(521,2214)$ & $0.0016^{*}$ \\
\hline 2nd Day after operation & 2197.5(1875) & $2130(1800,2465)$ & $1253.5(145,2087.5)$ & $0.0020^{*}$ \\
\hline 3rd Day after operation & $2180(2005,2615)$ & $2090(2000,2265)$ & $1365(75,2112.5)$ & $0.0002^{*}$ \\
\hline Mechanical ventilation (min) & 1020(780,2080) & $960(783,1380)$ & $3090(1550,6141)$ & $0.0033^{*}$ \\
\hline Time from operation to discharge (days) & $25(22,30)$ & $28(24,34)$ & $38(24.5,64)$ & $0.029^{*}$ \\
\hline Death & $7(11.29)$ & $0(0)$ & $8(50.00)$ & $0.0001^{*}$ \\
\hline Mortality in hospital & $4(6.45)$ & $0(0)$ & $7(43.75)$ & $<.0001^{*}$ \\
\hline Death within 1 year & $3(4.84)$ & $0(0)$ & $0(0)$ & 0.438 \\
\hline Follow-up days & $658.5(382,1162)$ & $954(489,2336)$ & $261(24.5736 .5)$ & $0.0028^{*}$ \\
\hline
\end{tabular}

* $P<0.05$; ANOVA was applied to the BMI variable because of its normal distribution. The Kruskal-Wallis test was used to compare other variables 
Table 4 Univariate and multivariate analysis of characteristics associated with in-hospital mortality

\begin{tabular}{|c|c|c|c|c|}
\hline & \multirow[t]{2}{*}{ OR } & \multicolumn{2}{|l|}{$95 \% \mathrm{Cl}$} & \multirow[t]{2}{*}{$P$ value } \\
\hline & & Lower-limit & Upper-limit & \\
\hline \multicolumn{5}{|l|}{ Univariate } \\
\hline Age, years $\geq 60$ & 4.333 & 1.071 & 17.534 & $0.0398^{*}$ \\
\hline CPB duration & 1.005 & 0.999 & 1.010 & 0.0940 \\
\hline Blood loss & 1.000 & 0.999 & 1.000 & 0.683 \\
\hline Urine volume & 1.000 & 0.999 & 1.000 & 0.247 \\
\hline IABP/ECMO & 10.125 & 1.746 & 58.700 & $0.0098^{*}$ \\
\hline AKI & 3.904 & 1.051 & 14.507 & $0.042^{*}$ \\
\hline AKI requiring $R R T$ & 11.278 & 2.740 & 46.424 & $0.0008^{*}$ \\
\hline \multicolumn{5}{|l|}{ Multivariate } \\
\hline $\begin{array}{l}\text { AKI requiring RRT } \\
(\text { ref }=\text { no-AKI and no-RRT) }\end{array}$ & 11.348 & 2.418 & 53.267 & $0.002^{*}$ \\
\hline IABP/ECMO & 2.302 & 0.299 & 17.743 & 0.424 \\
\hline
\end{tabular}

* $P<0.05$; OR Odds ratio, $C /$ Confidence interval, $C P B$ Cardiopulmonary bypass, $I A B P$ Intra-aortic balloon pump, ECMO Extracorporeal membrane oxygenation, $A K I$ Acute kidney injury, RRT Renal replacement therapy

dependence [15]. In this study, we found that mortality in hospital in patients with AKI was $21.21 \%$, and the incidence rate of AKI requiring RRT was 48.48\%. Moreover, overall survival in patients without AKI at 1 , and 3 years was higher than that in AKI patients.
In contrast to the high overall incidence of AKI, the need for RRT in our study was $16.84 \%$. This is similar to previous studies reporting a need for RRT in 6 to $29 \%$ of patients $[2,4,6]$. A recent analysis indicated that AKI requiring RRT had a 1-year mortality rate of $59.2 \%$ [16]. In Boyle's study, AKI requiring RRT was associated with a mortality rate of $50 \%$ compared to $1.4 \%$ in patients without AKI [17]. We estimated an increased risk for in hospital mortality, with an odd ratio of 11.348 in AKI patients requiring RRT. These results could be explained by the fact that patients with severe AKI are less likely to achieve full recovery of kidney function, even with RRT, than patients with mild AKI. In fact, some AKI patients requiring RRT develop at least one other serious complication (sepsis, graft failure, or acute myocardial infarction), which can lead to early mortality during the postoperative care period. In our study, seven patients in AKI with RRT group passed away in hospital. However, there was a nonsignificant tendency toward an increase in long-term mortality in AKI patients requiring RRT, which is consistent with previous reports [3]. Therefore, the impact of RRT appears to be lost at long-term follow-up. This result indicated that recovery of kidney function prior to hospital discharge was associated with decreased long-term mortality risk.

The interactions between the heart and kidney systems have become a matter of great concern [18]. The

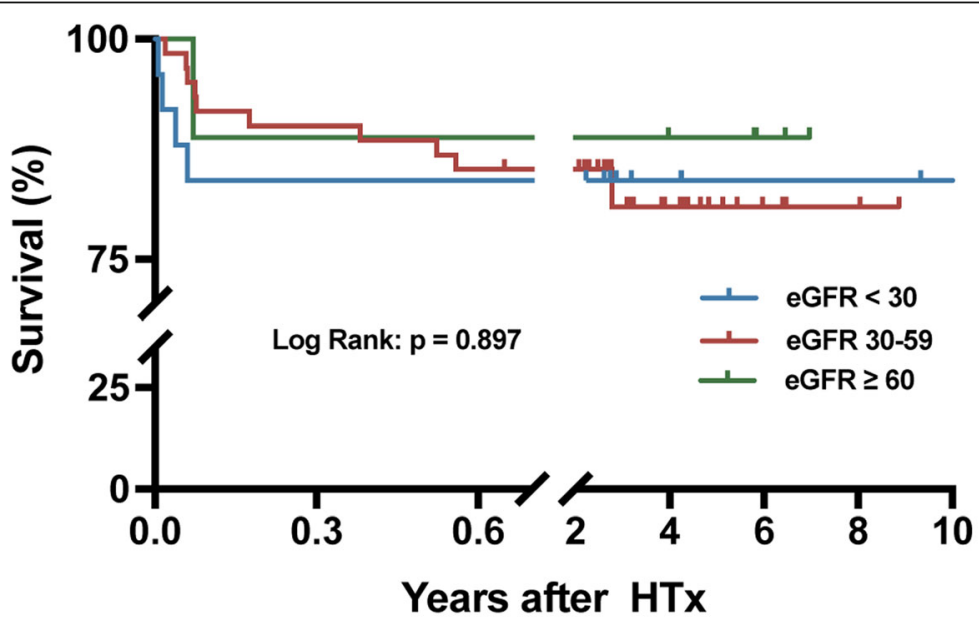

Number at risk

\begin{tabular}{lcccc}
\hline & Pre-operation & 30 days & 1 year & 3 year \\
\hline eGFR $<30$ & 25 & 21 & 17 & 4 \\
eGFR $30-59$ & 61 & 56 & 43 & 19 \\
eGFR $\geq 60$ & 9 & 8 & 8 & 5 \\
\hline
\end{tabular}

Fig. 1 Kaplan-Meier curves for overall survival. Analysis stratified by eGFR. eGFR, estimated glomerular filtration rate in $\mathrm{ml} / \mathrm{min} / 1.73 \mathrm{~m}{ }^{2}$ 


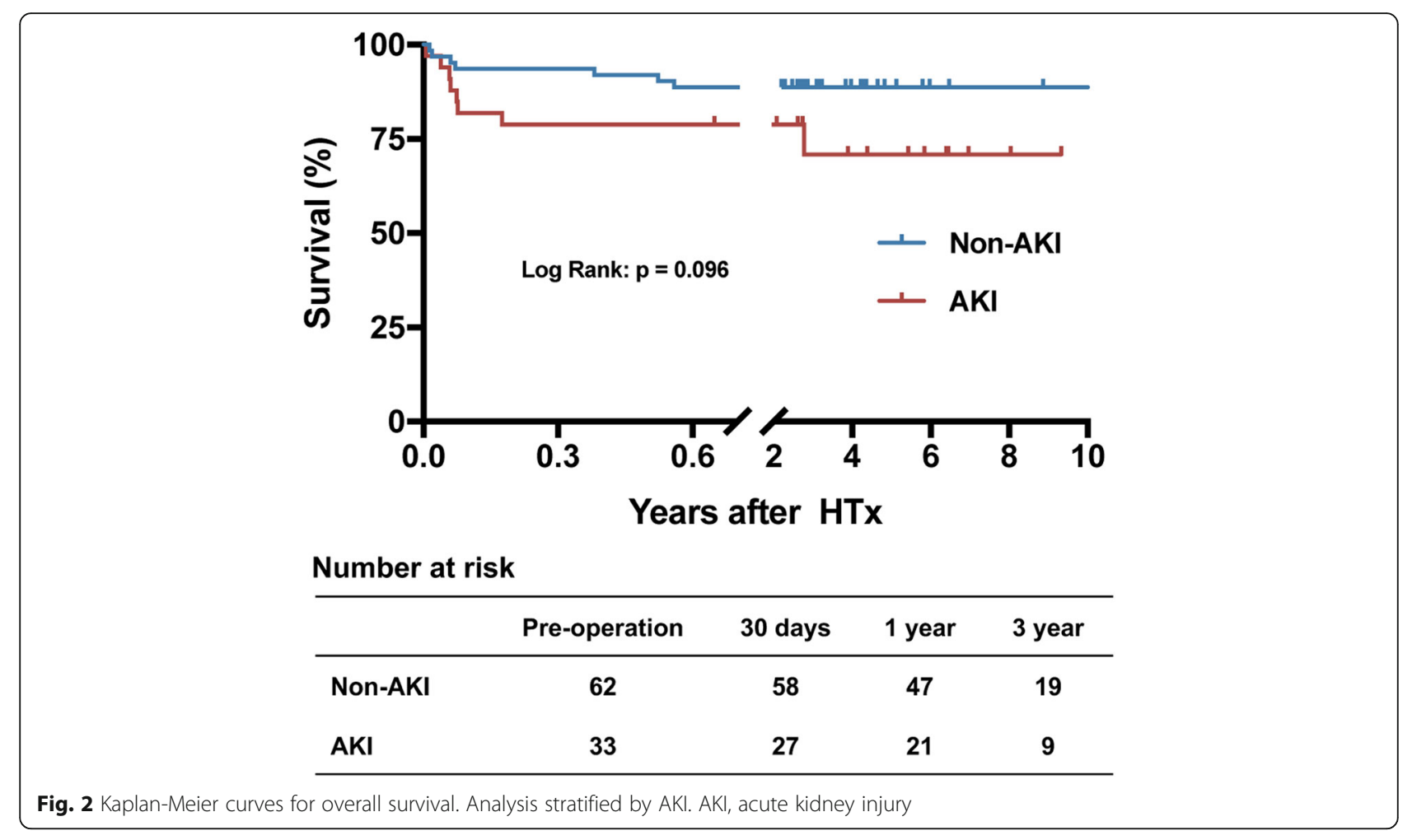

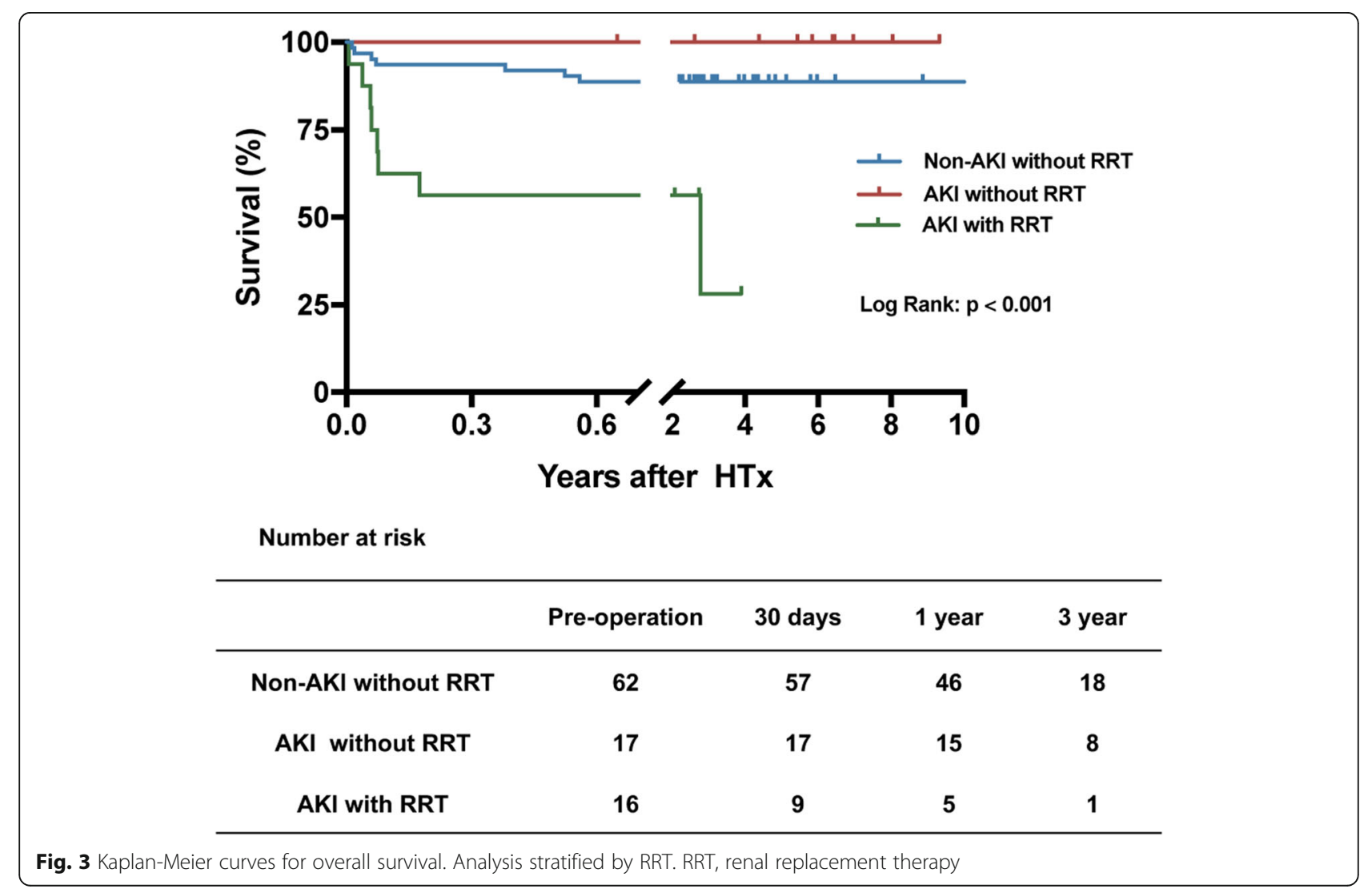


Table 5 Multivariate model for AKI

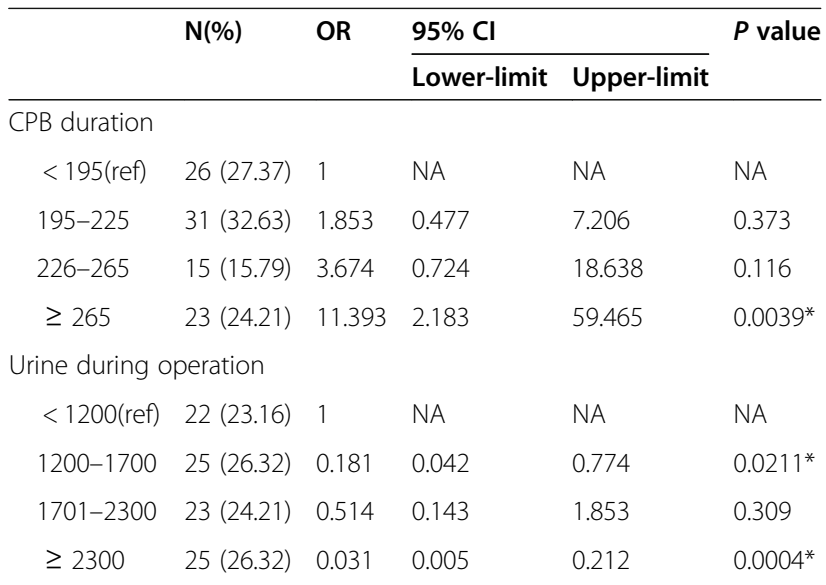

* $P<0.05$; OR Odds ratio, Cl Confidence interval, CPB Cardiopulmonary bypass, NA Not applicable, HR Hazard ratio, AKI Acute kidney injury, RRT Renal replacement therapy

difference between arterial driving pressure and venous outflow pressure must remain sufficiently large for adequate renal blood flow and glomerular filtration. The low-resistance nature of the renal vasculature and parenchyma and the very low oxygen tension in the outer medulla also explain the unique sensitivity of the kidneys to hypotension-induced injury [2, 19]. Thus, both hemodynamic instability and antecedent hypotension should be considered in the consultative evaluation of a patient with developing AKI.

Several factors have been suggested to contribute to the development of postoperative AKI. In general, the most common cause in the early postoperative period is ischemic-reperfusion injury [20]. Intraoperatively, maintenance of a mean arterial pressure (MAP) $>60-65 \mathrm{mmHg}$, reduction in CPB time, minimization of blood transfusion and avoidance of nephrotoxic agents may prevent AKI [2, 21]. Moreover, increased central venous pressure (CVP) was associated with a reduced GFR and all-cause mortality. Right atrial pressure strongly predicts the development of AKI early after HTx and can be used as an early AKI indicator [22]. Finally, postoperatively, chloride-restricted fluid management was associated with less AKI and RRT [23]. In our opinion, a relatively short $\mathrm{CPB}$ time and increased intraoperative urine volume play important roles in preventing the occurrence of AKI after HTx.

When AKI occurs, the most important thing is the time of applying RRT. It offers steady fluid removal and their intensity can be easily titrated for prevention or rapid administration of treatment of volume overload. This intervention in the postoperative management can prevent a higher progression of perioperative AKI, and the occurrence of the worst outcomes [24].

Although left ventricular assist device (LVAD) is widely applied as a bridge to HTx, kidney dysfunction is common after LVAD implantation. In theory, improvements in cardiac output after implantation of LVAD would be expected to improve renal perfusion. Previous studies shown that the improvement in renal function was seen during the first month postimplantation of LVAD and no further improvements occurred thereafter $[25,26]$. However, a decrease in renal function after implantation raising uncertainties about the longterm effects of continuous blood flow on renal function $[27,28]$. The incidence of postimplantation AKI is 7$14 \%$ in continuous-flow devices [29]. In addition, RRT is needed in a subset of patients who develop post-LVAD AKI [30]. In our study, a patient with non-pulsatile flow LVAD implantation developed AKI stage 2 before HTx but there is no AKI in post-HTx. We consider that the influence of LVAD on kidney do not affect the treatment effect of HTx.

The performance and usefulness of different AKI scoring systems with regard to mortality vary greatly [31]. The KDIGO criteria are widely applied in the analysis of AKI in HTx patients. However, the emphasis on $\mathrm{SCr}$ and urine volume may exaggerate the severity of AKI. In addition, according to the RIFLE criteria, AKI encompasses the entire spectrum of the syndrome, from minor changes in renal function to the requirement of RRT. Thus, AKI does not simply represent acute renal failure but is a more general description [32]. Since the AKIN criteria are not sensitive enough to capture all episodes of AKI in cardiac surgery patients, they are not widely used for HTx patients [33]. We consider to evaluate this issue in future clinical trials.

We acknowledge that several limitations exist in this study. The inherent limitation is that it was a retrospective, single-center study that enrolled a small number of patients. Furthermore, the small sample size made it difficult to detect small effects and prevented the accuracy of multivariate analysis. In addition, patients were relatively old and likely to suffer from comorbid conditions, such as diabetes mellitus and hypertension. These comorbidities may interfere with the analysis of the long-term survival rates in AKI requiring RRT. Finally, the indication for dialysis is standardized; however, to some extent, it depends on the physician treating the individual patient, which may have acted as a confounder in our study.

\section{Conclusions}

Our study suggests that AKI is a frequent complication of $\mathrm{HTx}$, and the results demonstrated that AKI requiring RRT following HTx was associated with an increased risk for for in-hospital mortality. However, AKI patients had a relatively good long-term prognosis, with the recovery of renal function. Therefore, the results of this study highlight that risk factor identification may assist in implementing strategies to prevent or limit the progression of AKI, which, in turn, may improve survival. 


\section{Abbreviations}

AKI: Acute kidney injury; HTx: Heart transplantation; KDIGO: Kidney Disease: Improving Global Outcomes; RRT: Renal replacement therapy; CPB: Cardiopulmonary bypass; RIFLEL: Risk/Injury/Failure/Loss/End-stage; AKIN: Acute Kidney Injury Network; SCr: Serum creatinine; ANOVA: One-way analysis of covariance; eGFR: estimated glomerular filtration rate; BMI: Body mass index; LVAD: Left ventricular assist device; LVEF: Left ventricular ejection fraction; DCM: Dilated cardiomyopathy; CAD: Coronary artery disease; PCl: percutaneous coronary intervention; IABP: Intra-aortic balloon pump; ECMO: Extracorporeal membrane oxygenation; OR: Odds ratio; $\mathrm{Cl}$ : Confidence interval

\section{Acknowledgments}

We thank Dr. HJ He and Dr. F Li for their assistance in statistical analysis.

\section{Authors' contributions}

Yiyao Jiang -Writing, Data collection, Statistics and Draft. Xiangrong Kong -Design, Reviewing. Fenlong Xue -Data collection. Honglei Chen -Data collection. Wei Zhou -Data collection. Junwu Chai- Data collection. Fei Wu -Draft. Shanshan Jiang -Draft. Zhilong Li -Statistics. Kai Wang -Writing. The authors read and approved the final manuscript.

\section{Funding}

This work was supported by grants from the National Natural Science Foundation of China (81800214), Natural Science Foundation of Anhui Province (1808085QH236).

\section{Availability of data and materials}

The datasets used and/or analyzed during the current study are available from the corresponding author on reasonable request.

\section{Ethics approval and consent to participate}

The study was approved by the Institutional Ethical Review Board of Tianjin First Center Hospital. The need for patient consent was waived due to the retrospective study design.

\section{Consent for publication}

Not applicable.

\section{Competing interests}

The authors declare that they have no competing interests.

\section{Author details}

${ }^{1}$ Department of Cardiovascular Surgery, Tianjin First Center Hospital and NanKai University, Tianjin, China. ${ }^{2}$ Department of Cardiovascular Surgery, The First Affiliated Hospital of Bengbu Medical College, Bengbu, Anhui Province, China.

Received: 18 May 2020 Accepted: 28 September 2020

Published online: 07 October 2020

\section{References}

1. Dellgren $\mathrm{G}$, et al. Three decades of heart transplantation in Scandinavia: long-term follow-up. Eur J Heart Fail. 2013;15(3):308-15.

2. De Santo LS, et al. Implications of acute kidney injury after heart transplantation: what a surgeon should know. Eur J Cardiothorac Surg. 2011;40(6):1355-61.

3. Gude $E$, et al. Acute renal failure early after heart transplantation: risk factors and clinical consequences. Clin Transpl. 2010;24(6):E207-13.

4. Wyatt CM, Arons RR. The burden of acute renal failure in nonrenal solid organ transplantation. Transplantation. 2004;78(9):1351-5.

5. Türker M, et al. RIFLE criteria for acute kidney dysfunction following heart transplantation: incidence and risk factors. Transplant Proc. 2013;45(10): 3534-7

6. Escoresca Ortega AM, et al. Kidney failure after heart transplantation. Transplant Proc. 2010;42(8):3193-5.

7. Fortrie $\mathrm{G}$, et al. Acute kidney injury as a complication of cardiac transplantation: incidence, risk factors, and impact on 1-year mortality and renal function. Transplantation. 2016;100(8):1740-9.
8. Rangaswami J, et al. Cardiorenal syndrome: classification, pathophysiology, diagnosis, and treatment strategies: a scientific statement from the American Heart Association. Circulation. 2019;139(16):e840-78.

9. Zappitelli $\mathrm{M}$, et al. Ascertainment and epidemiology of acute kidney injury varies with definition interpretation. Clin J Am Soc Nephrol. 2008; 3(4):948-54.

10. Mehta RL, et al. Acute kidney injury network: report of an initiative to improve outcomes in acute kidney injury. Crit Care. 2007;11(2):R31.

11. Khwaja A. KDIGO clinical practice guidelines for acute kidney injury. Nephron Clin Pract. 2012;120(4):c179-84.

12. Arnol M, Kneževič I. Kidney dysfunction after cardiac transplantation: does early acute kidney injury translate into inferior long-term patient and renal outcomes? - a retrospective cohort study. Transpl Int. 2017;30(8):785-7.

13. Thongprayoon $\mathrm{C}$, et al. Acute kidney injury in patients undergoing cardiac transplantation: a meta-analysis. Medicines (Basel). 2019;6(4):108.

14. García-Gigorro R, et al. Incidence, risk factors and outcomes of early acute kidney injury after heart transplantation: an 18-year experience. Transplantation. 2018;102(11):1901-8.

15. Fortrie $\mathrm{G}$, et al. Renal function at one year after cardiac transplantion rather than acute kidney injury is highly associated with long-term patient survival and loss of renal function- a retrospective cohort study. Transpl Int. 2017;30: 788-98.

16. Romeo FJ, et al. Acute kidney injury after cardiac transplantation: foe or common innocent bystander? Transplant Proc. 2018;50(5):1489-95.

17. Boyle $\mathbf{J M}$, et al. Risks and outcomes of acute kidney injury requiring dialysis after cardiac transplantation. Am J Kidney Dis. 2006;48(5):787-96.

18. Costanzo MR. The Cardiorenal syndrome in heart failure. Heart Fail Clin. 2020;16(1):81-97.

19. Badin J, et al. Relation between mean arterial pressure and renal function in the early phase of shock: a prospective, explorative cohort study. Crit Care. 2011;15(3):R135

20. Malek M, Nematbakhsh M. Renal ischemia/reperfusion injury; from pathophysiology to treatment. J Renal Inj Prev. 2015;4(2):20-7.

21. Leone $M$, et al. Optimizing mean arterial pressure in septic shock: a critical reappraisal of the literature. Crit Care. 2015:19:101.

22. Guven $\mathrm{G}$, et al. Preoperative right heart hemodynamics predict postoperative acute kidney injury after heart transplantation. Intensive Care Med. 2018;44(5):588-97.

23. Yunos NM, et al. Association between a chloride-liberal vs chloriderestrictive intravenous fluid administration strategy and kidney injury in critically ill adults. JAMA. 2012;308(15):1566-72.

24. Kwon JT, Jung TE, Lee DH. Predictive risk factors of acute kidney injury after on-pump coronary artery bypass grafting. Ann Transl Med. 2019;7(3):44.

25. Brisco MA, et al. Prevalence and prognostic importance of changes in renal function after mechanical circulatory support. Circ Heart Fail. 2014; 7(1):68-75.

26. Yoshioka D, et al. Changes in end-organ function in patients with prolonged continuous-flow left ventricular assist device support. Ann Thorac Surg. 2017;103(3):717-24.

27. Kirklin JK, et al. Seventh INTERMACS annual report: 15,000 patients and counting. J Heart Lung Transplant. 2015;34(12):1495-504.

28. Slaughter MS, et al. HeartWare ventricular assist system for bridge to transplant: combined results of the bridge to transplant and continued access protocol trial. J Heart Lung Transplant. 2013;32(7):675-83.

29. Patel $\mathrm{AM}$, et al. Renal failure in patients with left ventricular assist devices. Clin J Am Soc Nephrol. 2013;8(3):484-96.

30. Topkara VK, et al. Preoperative proteinuria and reduced glomerular filtration rate predicts renal replacement therapy in patients supported with continuous-flow left ventricular assist devices. Circ Heart Fail. 2016;9(12): e002897.

31. Schiferer A, et al. Acute kidney injury and outcome after heart transplantation: large differences in performance of scoring systems. Transplantation. 2016;100(11):2439-46.

32. Tjahjono R, Connellan M, Granger E. Predictors of acute kidney injury in cardiac transplantation. Transplant Proc. 2016;48(1):167-72.

33. Sutherland $L$, et al. Acute kidney injury after cardiac surgery: a comparison of different definitions. Nephrology (Carlton). 2020;25(3):212-8.

\section{Publisher's Note}

Springer Nature remains neutral with regard to jurisdictional claims in published maps and institutional affiliations. 